\title{
LA PINTURA DEL SIGLO XIX EN LATINOAMÉRICA: EN TORNO A UNA VISIÓN AMERICANA
}

Por Rita Eder

El dilema ya planteado a fin del siglo xix y principios del $\mathrm{xx}$ por pensa dores como el uruguayo José Enrique Rodó y el mexicano José Vascor celos, acerca de la especificidad de la cultura latinoamericana, ha preocupado en forma cíclica, a quienes se dedican a pensar sobre las expresiones artísticas en América Latina.

Hacia la década de los años treinta, artistas, críticos y teóricos parecieron encontrar algunas respuestas satisfactorias en las soluciones que a este problema antepusieron, la Escuela Mexicana de Pintura, el Universalismo Constructivo de Torres García en el Uruguay y el movimiento indigenista del Perú con Sabogal a la cabeza. Sin embargo, el problema de la identidad artistica latinoamericana ha cobrado renovada importancia dado el indiscutible fenómeno de la internacionalización de las artes. Ello mismo obstaculiza, al tiempo que propicia, la meditación sobre la diferenciación de las expresiones artísticas latinoamericanas en relación al arte europeo y norteamericano, provocando frente al argumento cerrado de dicha internacionalización que críticos y teóricos se refugien en proposiciones utópicas y propongan una teoría del "deber ser" del arte en América Latina a modo de solución.

El problema así planteado exige una distinta formulación crítica de las proposiciones utópicas, y que apunte hacia una revisión concep. tual que se extienda hasta el arte colonial.

La historia del arte en América Latina, por lo menos a partir de la Conquista, ha sido descrita, analizada e interpretada a través de diversas formulaciones teóricas que proceden de la visión europea del arte. Ello se manifiesta no sólo en la aplicación de distintas concepciones estéticas sino también, y sobre todo, en la utilización de categorias estilísticas que caracterizan los cambios en el vocabulario formal que se manifiesta en el desarrollo de las artes. Sin duda ello constituye un mal necesario, ya que el historiador de arte necesita de un instrumento de trabajo que le permita agrupar y diferenciar el quehacer artístico.

Sin embargo, la adopción de este sistema de trabajo no resulta únicamente en un método inocente para la mejor ubicación de las obras, sino que las consecuencias son graves para ubicarse frente a la realidad artística de Latinoamérica. Las categorías estilísticas se basan sobre los 
cambios de forma y contenido que aparecen en un determinado periodo histórico, expresando una posible heterogeneidad de situaciones que surgen dentro de la vida social y espiritual de una comunidad. Si tomamos como punto de partida que la aplicación de las categorías, que de esta concepción derivan, fueron formuladas para el arte europeo, es inevitable que presenten un método sui géneris en cuanto son adaptadas a la producción artística latinoamericana, ya que su papel de "heredera de la cultura de Occidente" no implica una condición de mimesis cultural sino que apunta a un carácter distinto implícito tanto en sus propios orígenes como en las intenciones utópicas de sus colonizadores. Este modo propio de ser aparece en forma compleja en los objetos artísticos, y sus formas de realización chocan con los cánones contenidos en las diferentes formulaciones de un determinado estilo. La más grave consecuencia de este fenómeno es la negación de estos objetos, estructuras, etcétera, en cuanto expresivos de un modo de arte.

El arte en Latinoamérica, en la época colonial, en el siglo xrx y aún actualmente, no se conforma en muchas ocasiones a la secuencia estilística europea y más bien presenta un carácter ecléctico, así como muchas veces impone la presencia de un ojo inocente que se traduce en una muy diferenciada realización plástica con respecto a la europea.

Éstas, entre otras razones, están exigiendo una nueva metodología y teoría con la cual acercarse al arte realizado en América Latina.

No cabe duda que tal proposición puede parecer pretenciosa más que ambiciosa; sin embargo, el no intentarlo cierra las puertas a cualquier aspiración de asomarnos a nuestro mundo con una mirada fresca que dé otras posibilidades a la visión encajada que hemos heredado.

El momento más polémico de la aproximación tradicional ya planteada, se presenta al considerar el desarrollo de la pintura del siglo XIX en Latinoamérica. En general y con toda libertad se ha afirmado que ésta presenta una aproximación formal que muestra las características de las dos grandes corrientes que dominan la pintura de la primera mitad del siglo xix en Europa: el neoclasicismo y el romanticismo. A grandes rasgos puede afirmarse que en esta época en los distintos países latinoamericanos, el proceso de la pintura presenta características en común. Las academias y escuelas de pintura que surgen primero en México, hacia 1785, y en el Brasil, en 1815, se multiplican en los distintos países y propician una pintura académica cuya enseñanza estará en manos de maestros europeos y poco más tarde será realizada por artistas criollos. Paralelamente a ello se da una expresión más libre 
DOI: http://dx.doi.org/10.22201/iie.18703062e.1977.47.1086

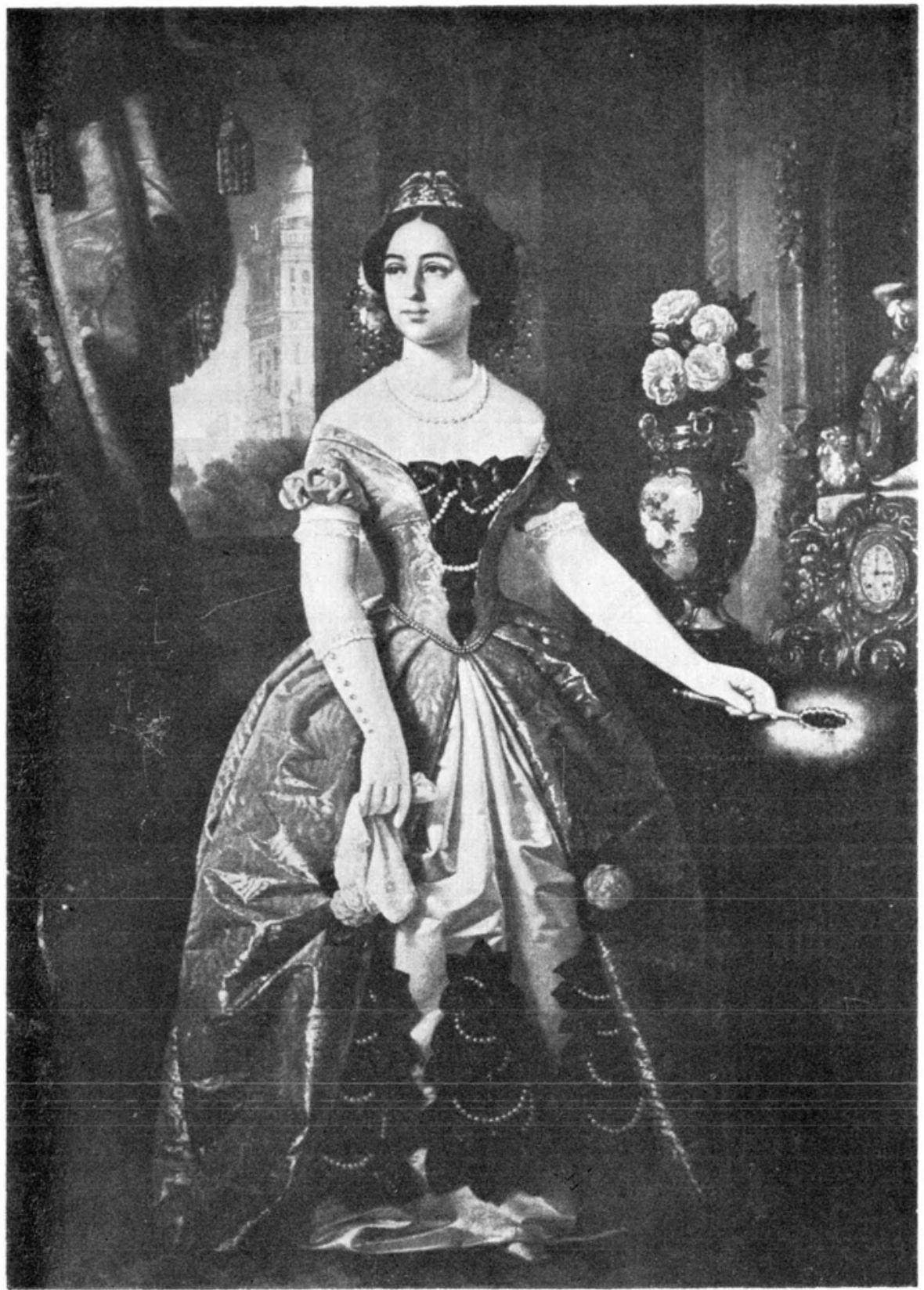

Figura 1. Juan Cordero. Dolores Tosta de Santa Anna. 


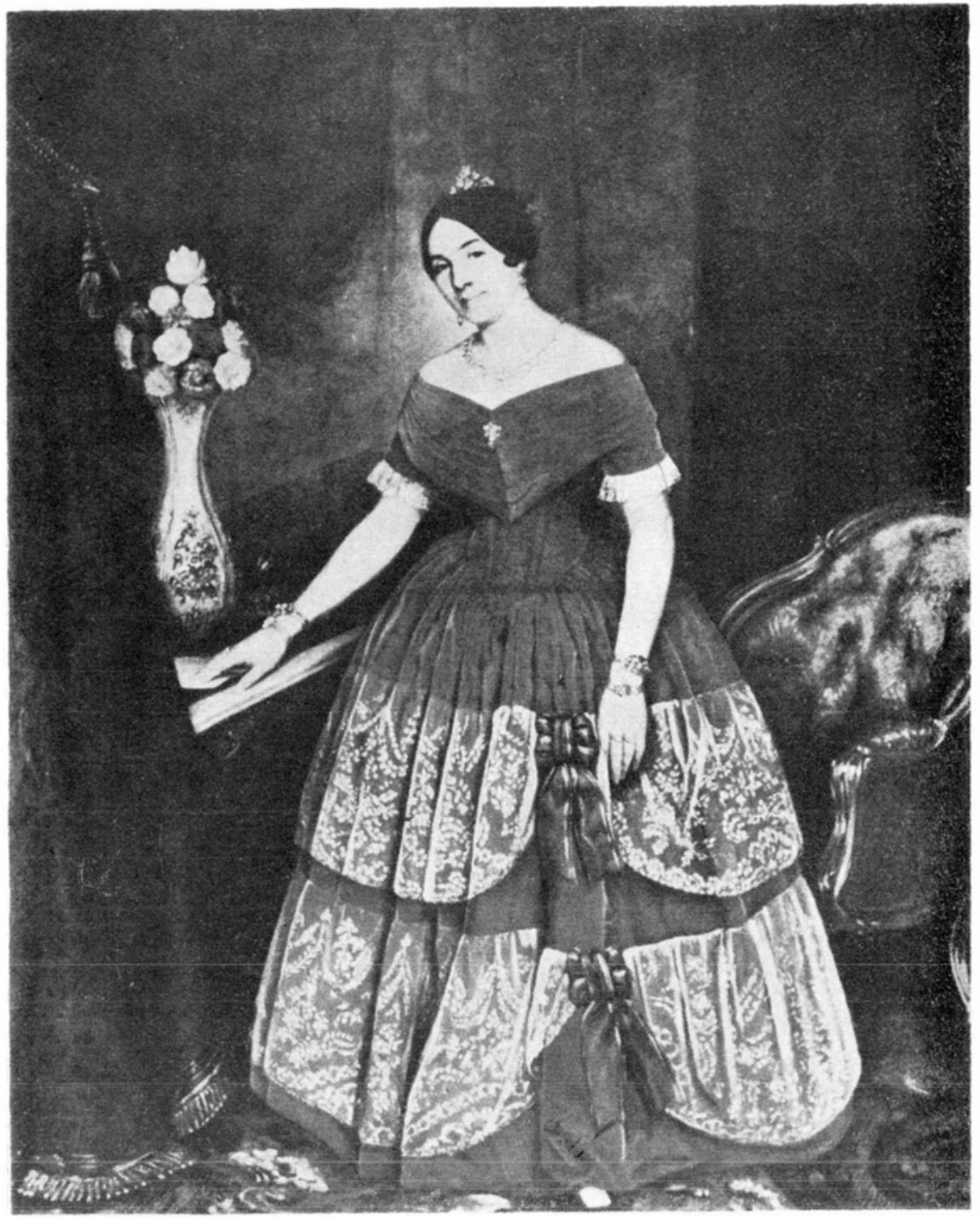

Figura 2. Pirilidiano Pueyrredón. Manuelita Rosas. 
DOI: http://dx.doi.org/10.22201/iie.18703062e.1977.47.1086

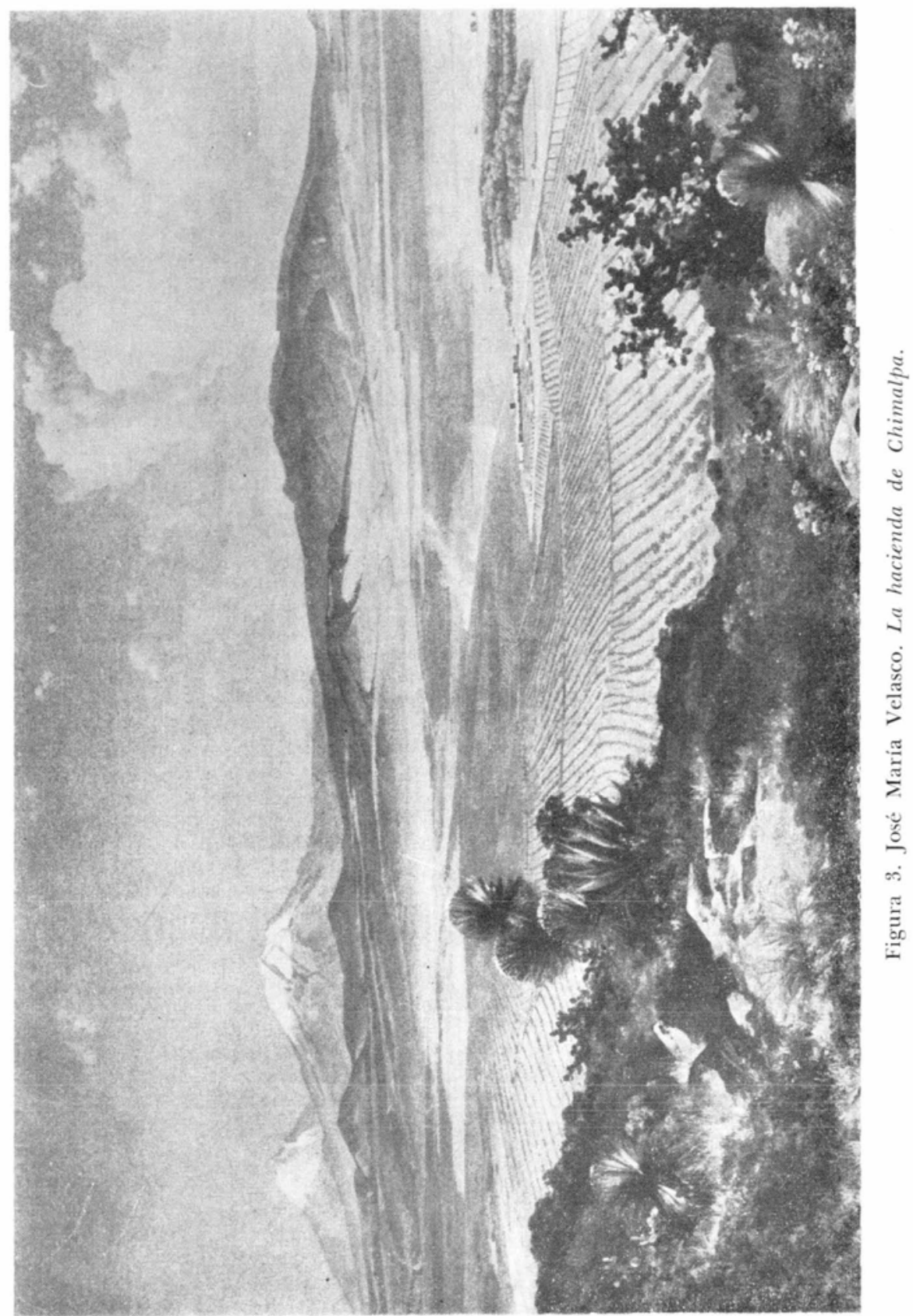


DOI: http://dx.doi.org/10.22201/iie.18703062e.1977.47.1086 
y espontánea que está íntimamente ligada a la llegada de viajeros extranjeros, ya sea a cargo de misiones científicas of por la inquietud, típica de esta época, de adentrarse en un mundo exótico. También hubo quienes vinieron por un interés no precisamente romántico de explorar los recursos naturales del continente. Este último factor merecería un capítulo aparte, ya que poca atención se ha concedido a los factores socioeconómicos que intervienen en la formación de nuestra visión del arte.

Estos expedicionarios revelarán en sus dibujos, acuarelas, litografías y pinturas al óleo escenas de la vida cotidiana, creando un género costumbrista que, trasladado a Europa para ser reproducido en diversos álbumes, formará la imagen que los europeos tuvieron de la América Latina en el siglo xrx; asimismo, una serie de pintores nativos proseguirán esta misma tendencia costumbrista. Ambas tendencias, la académica y la iniciada por los viajeros, serán ubicadas por los estudiosos bajo la tiranía de las tendencias dominantes en Europa ya mencionadas. Al neoclasicismo correspondería la pintura de retrato individual o de grupo, supuestamente a la manera de Mengs o de Ingres, más la representación de batallas con elementos de la mitología griega. En el caso del Brasil, algunos eventos en torno a la corte portuguesa en Bahía serán equiparados a las representaciones de la corte napoleónica realizados por Jacques Louis David. Dentro del romanticismo se incluye también el retrato, en este caso inspirado en Delacroix, así como escenas costumbristas, el paisaje de descripción arqueológica, etcétera.

Un enfrentamiento con las obras mismas aclara rápidamente lo forzado del esquema estilístico en cuanto es aplicado a la pintura latinoamericana; es decir, resulta difícil encontrar en estas obras, salvo excepciones importantes, el neoclasicismo europeo o el romanticismo, tendencias por otro lado con un significado muy específico, en el ámbito de la Europa Occidental.

La confrontación con el esquema estilístico hace que distintas obras realizadas en Latinoamérica aparezcan como manifestaciones provin. ciales o en el mejor de los casos como una seudoexpresión de la pintu1a europea. Frente a este callejón sin salida es neosario adoptar otro punto de vista; es decir, no agrupar las tendencias de la pintura en Latinoamérica bajo las grandes nomenclaturas europeas, por lo menos sin aclarar cómo y para qué sirven, a la vez que intentar un nuevo acercamiento que la disciplina que conocemos como la historia del arte está exigiendo. Existe actualmente una fuerte corriente de opinión que acepta que el historiador de arte no pueda contentarse sólo con los 
métodos propios de su especialidad. Si quiere ofrecer una visión más reveladora del fenómeno artístico tiene que aceptar un enfoque interdisciplinario.

E. H. Gombrich ha manifestado, al lado de una gran cantidad de especialistas, la urgencia de tal transformación dentro de la historia del arte. En su importante libro Art and illusion pone en duda las actuales y aceptadas teorías del estilo y propone, como método colateral, el proceso visual no como un mecanismo físico sino como un conjunto de procesos psicológicos, en cierta medida socialmente determinados, que revierten sobre la visualidad.

Desde este punto de vista la teoría de la percepción en vez de apoyarse en las semejanzas estilísticas, hace alusión a las diferencias y se pregunta por qué el mundo visible ha sido representado en forma distinta a través del tiempo.

Esta forma de pensar el proceso artístico puede ser útil para revaluar la pintura del siglo xix en México, y no analizarla sólo en términos de su relación con el arte europeo sino en términos de una tradición de la visibilidad que se origina desde América a partir de la Colonia. Este enfoque no pretende responder adónde reside la mexicanidad del arte mexicano, sino más bien contestar al cómo se convierte en mexicano, ya que no sólo se trata de reconocer las cualidades propias sino el proceso de transformación en la pintura mexicana de la tradición europea. Para ello me serviré de dos ejemplos importantes, se trata de dos pintores del siglo pasado: Juan Cordero en el género del retrato y José Ma Velasco en el paisaje.

\section{JUAN CORDERO (1824-1894)}

La pintura de Juan Cordero ha sido definida como perteneciente al clasicismo romántico, sin olvidar que esta categoría nos sirve para ubicarlo dentro de una determinada tradición pictórica europea, un análisis de su obra muestra incongruencias con este concepto.

Cordero cultivó el retrato individual y de grupo, excepcionalmente los temas mitológicos. Testigo aún del peso y la importancia de la tradición colonial en Latinoamérica, Cordero produjo una considerable cantidad de pinturas religiosas.

Sin dejar de advertir sus cualidades de buen dibujante, hay en su obra factores que lo separan de la tradición europea y lo remiten a una forma de representación visual, común en América a partir de la Colo- 
nia, que se muestra sobre todo en el retrato. Las diferencias entre los procesos artísticos propios de América y Europa son visibles en la manera de representar la ilusión de la realidad; es decir, como ha sugerido Gombrich, ningún pintor es realmente capaz de plasmar lo que ve, como querian en última instancia los impresionistas, sino que proyecta desde lo que conoce. El artista trabaja de acuerdo con un esquema previo y a partir de él va cambiando y corrigiendo hasta obtener una imagen que aparece como la reproducción de la realidad, entre mayor capacidad combinatoria tenga el pintor más real aparecerá la imagen. Una de las características del retrato en Latinoamérica, con la excepción de maestros europeos como Ximeno y Planes y otros, es el conflicto con esta ilusión perfecta, ello se debe a una tendencia más conceptual y abstracta dada la falta de una prolongada tradición académica.

La frescura de la pintura de Cordero procede de una relación complicada entre objeto e idea, prevalece la tendencia conceptual de lo representado sobre la imagen ilusoria de la realidad. El retrato de Doña Dolores Tosta de Santa Anna (figura 1), en el campo del retrato, ejemplifica este punto de vista: la figura femenina muestra una silueta dura y contenida, con un gran énfasis en los adornos del vestido que cobran exagerado volumen, los brazos no parecen articulaciones móviles, más bien aparecen, casi sorpresivamente, al emerger de las mangas del vestido.

La figura domina el cuadro y los elementos arquitectónicos aparecen como separados del cuerpo de la mujer, hay una adecuación a las sofisticaciones del retrato europeo, pero prevalece una visión frontal algo esquuemática que recuerda la tradición anónima del retrato colonial, lo mismo se impone claramente en el cuadro realizado en 1875 Las hijas de don Manuel Cordero. Curiosamente más que encontrar relación con la pintura de Ingres, puede hermanarse esta pintura de Cordero (la señora de Santa Anna) con la del argentino Pirilidiano Pueyrredón, que alrededor de la misma época pinta a la hija (Manuelita) (figura 2) de un caudilio argentino, don Juan Manuei de Rosas.

El dibujo conceptual, a veces esquemático, de Cordero se mantiene en varios de los géneros cultivados por el pintor. Un ejemplo clave es la Muerte de Atala, posiblemente realizada en 1847 , y varios de los temas religiosos tales como Jesús entre los doctores de 1856.

He señalado la semejanza de concepción entre Cordero y Pueyrredón, en cierta manera, para insistir en que Cordero no es un caso aislado, todo lo contrario, es posible encontrar en Latinoamérica numeroso pin- 
tores que presentan las mismas características de ejecución como para pensar que entre sí forman una especie distinta de la europa. La observación de su proceso pictórico sirve no para ver si entendieron o no las lecciones europeas, sino para visualizar cómo lo transformaron de acuerdo con una determinada tradición ya existente en América, relacionada con una manera predominantemente conceptual de acercamiento a la realidad.

\section{JOSÉ MARÍA VELASCO}

La pintura de paisaje en México y Latinoamérica se introdujo como rema obligado por los viajeros extranjeros. En general prevalece el género romántico, derivado de una actitud mistificadora de la naturaleza que se origina en el siglo xvir. La gran innovación de Velasco (figura 3), sobre los maestros europeos, consistía en una relación distinta con el objeto representado. A pesar de ser un gran maestro del color, preva. lece en él su relación característica con la realidad y da lugar a una poesía de la realidad objetiva; no es la poesía del poeta con respecto a las cosas, sino la poesía de las cosas mismas. La naturaleza deja de ser un símbolo para ser ella misma.

Estamos frente a un ojo sobrenatural que capta el paisaje como una superficie brillante, el artista pareciera suspenderse y el momento aparece aprisionado en una casi ordenación matemática de los planos.

La pintura de Velasco lleva una serie de consideraciones acerca de la naturaleza de su invención artística. La pintura de paisaje pretendió ser mayormente perceptual en términos de luz y color, mientras que la obra de Velasco se inscribe dentro de un mayor conceptualismo, controlada por lo que la mente sabe del carácter o esencia de un objeto. Su pintura ilustra e ilumina el ojo de la mente a través de un espacio potente y amplio. El espectador se siente empequeñecido en este mundo de Velasco, que le introduce a la infinita vastedad de la naturaleza, representado por una geometría cuidadosamente compuesta por el color; la línea del horizonte pareciera lo mayormente acentuado y nos atrapa en base a un intenso realismo, en un mundo que oscila entre la anatomía de la naturaleza y la intensa animación de elementos naturales cosificados.

La visión conceptual de la realidad domina la pintura del siglo xrx en Latinoamérica. Ello se hace más obvio en la gran cantidad de pintura popular existente, sobre todo en México y en el Perú. Las ideas aquí 
expuestas son sólo un intento rudimentario de ahondar en las diferencias que existen entre la visión americana, y la europea con respecto al mundo circundante. No conducirá a nada la comparación entre unas y otras mientras no se tenga en cuenta que estamos frente a una serie de pintores que amalgaman la tradición americana con las lecciones europeas, que dan lugar a una realización plástica distinta que, la cual, por una actitud predominante conceptual, crea una relación de suyo distinta con el objeto, produciendo con ello una pintura, agradable y anecdótica en la pintura popular, pero que en José María Velasco se convierte en expresión monumental. 